\title{
ENHANCEMENT OF PERFORMANCE OF FILTER USING DEEP BED MONO MEDIA WITH ALUM AS FILER AID
}

\author{
Manoj H Mota \\ Research Scholar, Rajarambapu Institute of Technology, Rajararamnagar, \\ Islampur \& Assistant Professor, Civil Engineering, Sharad Institute of Technology, \\ College of Engineering, Shivaji University, India \\ Dr. P S Patil \\ Professor, Civil Engineering, Rajarambapu Institute of Technology, \\ Rajararamnagar, Islampur, India \\ Dr. V D Salkar \\ Professor, Civil Engineering, Walchand College of Engineering, Sangli, India
}

\begin{abstract}
The use of filter aid to improve the performance of conventional rapid sand filter $(R S F)$ is a relatively new development in drinking water treatment. Different advantages claimed by such use of filter aid includes reduction in ripening period, higher turbidity removal as well as relatively stable effluent quality while the limitations includes the reduction in filter rate as well as reduction in filter run. To overcome these limitations, the attempt is made to devise the RSF by increasing the effective size (around $0.85 \mathrm{~mm}$ ) and lowering the coefficient of uniformity of media (around 1.2) with use of alum solution as a filter aid. The study is conducted at one of the water treatment plant at Ichalkaranji, Maharashtra by installing a pilot scale model. The results are very encouraging. High turbidity removal, extended filter run and net reduced backwashing requirement are the prominent features observed.
\end{abstract}

Key words: filter aid, effective size, coefficient of uniformity, turbidity removal, pilot scale model.

Cite this Article: Manoj H Mota, Dr. P S Patil, Dr. V D Salkar, Enhancement of Performance of Filter Using Deep Bed Mono Media with Alum as Filer Aid, International Journal of Advanced Research in Engineering and Technology, 10 (3), 2019, pp 156-168.

http://iaeme.com/Home/issue/IJARET?Volume=10\&Issue $=3$

\section{INTRODUCTION}

Filtration has been extensively used, following treatment of raw waters by chemical coagulation, flocculation, and sedimentation processes in most of the conventional treatment 
plants in India. It is a fundamental unit process that is commonly used tore move particulate matter in the treatment of drinking water. Sand media is a one of the most critical component of most rapid sand filters. Conventionally for a silica sand the effective size is in the range of $0.35 \mathrm{~mm}$ to $0.55 \mathrm{~mm}$ with maximum size of $1 \mathrm{~mm}$ and the uniformity coefficient ranges between 1.3 and 1.7. Smaller effective size result in higher pressure losses in the filter and shorter operating cycles between cleaning, on other hand higher effective size will result in low pressure losses and higher operating cycle with inferior quality of product water.

\subsection{Operational cycle}

During the operational cycle of conventional rapid filtration, which typically ranges from 12 to $36 \mathrm{~h}$, three phases can be distinguished as indicated in figure 1 .

(1) A ripening or maturating stage, at the beginning of the filter run is characterized by low head loss and low particle removal. The duration of the ripening period in rapid sand filters depends on the backwash procedure, influent characteristics, and backwash water chemistry as well as few other factors like amount and characteristics of remnant particles [1]. It may last from few minutes to several hours [1,2] While keeping correct chemical regime, insufficient removal of pathogenic microorganisms can be safely attributed to the ripening stage with low performance of newly backwashed filter.

(2) A working stage, during which the filter performance is best possible and the head loss gradually increases due to gradual clogging of filter media.

(3) A breakthrough stage during which turbidity removal gradually reduces and the head loss accumulates rapidly, affecting the filtration rate. $[3,4]$

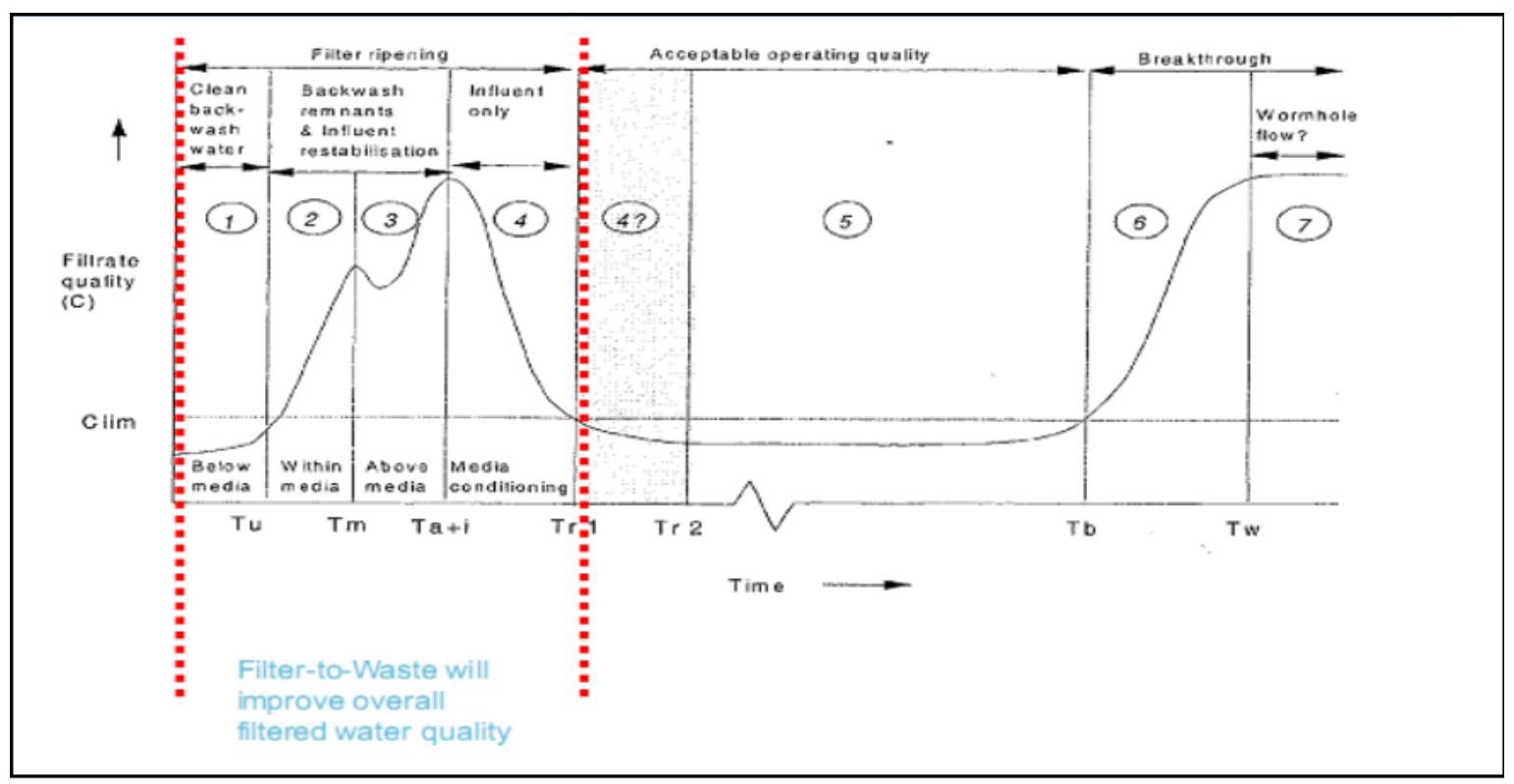

Figure 1 Typical filter run, particle count and turbidity (Origin: OTCO water workshop, March 27,2012)

\subsection{Development of head loss}

The head loss occurs when clean water flows through a bed of clean filter media and is go on increasing as the pores are getting filled by the dirt removed in the filtration process resulting in clogging of media. The head loss is the function of grain density, bed porosity and sphericity of the filter media. Typical head loss in conventional RSF is around $2.5 \mathrm{~m}$ to $3 \mathrm{~m}$. 


\subsection{Effect of humic substances present in water}

Humic substances are always affecting the performance of rapid sand filter adversely by reducing particle capture [5]. Humic substances comprise a fraction (ranging between $40 \%$ to $60 \%$ ) of dissolved organic matter in natural water bodies like river [6]. Along with their negative effect on filtration, humic substances are undesirable in a potable water supply for a various reasons, ranging from inferior aesthetics to possible production of potentially carcinogenic disinfection by-products (DBPs) in the presence of chlorine. [7,8]. Humic substances have properties of anionic polyelectrolytesand carry weakly acidic functional groups, including carboxylic and phenolic and groups [6]. Dissolved aquatic humic substances, which are net negatively charged macromolecules because of the ionization of those acidic functional groups, can adsorb onto the surface of clay and other natural particles, further increasing their negative charge [7]. In India most of the plants have the river water as source. India being the country having a very large agricultural practices most of such activities are conducted along the river bank, releasing very high amount of humic substances from the agricultural run-off into the river water. This makes the job of water treatment plants and filters in particular, very difficult.

Few researchers have proposed various unique ways to improve the filter performance like replacing down flow filters by up-flow filters.[8]. But such modification in infrastructure of existing water treatment plant in India may not be possible because of financial constraint as well as availability of expertise.

The effective and easy way to overcome all these hurdles is to use pre-treatment of filter media with coarser configuration with lower coefficient of uniformity (Mono media).

The use of filter aid as pre-treatment to improve the performance of conventional rapid sand filter is a relatively recent development in drinking water treatment. Different advantages claimed by such use of filter aid includes reduction in ripening period, higher turbidity removal as well as relatively stable effluent quality while the limitations includes the reduction in filter rate as well as reduction in filter run. $[9,10,11,12,13]$.

The concept is more successful for dual media which is very common in western countries. But in developing countries like India the filter media like anthracite coal is scare and hard to get. In such case the utilization of sand media is the most feasible option. To overcome the limitations of pretreated filtration, the possible way is to utilize coarser mono media with appropriate dose of alum aid.

The study focuses on such aspect associated with the modification of conventional filter media and use of alum as filter aid. In the initial part of research, various alum doses were tried on conventional filter media to understand the advantages and limitations of such modifications on the filtration process and later the possible measure were studied and tested to overcome the limitations observed. In the research described in the paper, the attempt is made to devise the RSF with increased effective size (about $0.85 \mathrm{~mm}$ ) and low the coefficient of uniformity of media (about 1.2) with use of alum solution as a filter aid. The results are very encouraging.

The study is conducted at one of the water treatment plant at Ichalkaranji, Maharashtra by installing a pilot scale model. The sources for this plant are river Panchganga and river Krishna. The original capacity of plant was 54MLD which has recently augmented to 108 MLD. Large amount of agricultural activities are practiced on the banks of these rivers, because of which the concentration of humic substances found in the water is very high. The settled wateris used for the research. 


\section{MATERIAL AND METHODS}

\section{Following methodology was adopted for the study}

- The sand media of desired effective size and uniformity coefficient was prepared by sieving the washed and sun dried stock sand available at Ichalkaranji WTP. The filter media with conventional configuration was prepared having effective size $0.5 \mathrm{~mm}$ and coefficient of uniformity 1.7.Along with this, the media having coefficient of uniformity as 1.2 and effective size $0.85 \mathrm{~mm}$ was also prepared as innovative media.

- A pilot scale model of filter was constructed using two glass columns with an inside dimension of $0.15 \mathrm{~m} \mathrm{X} 0.15 \mathrm{~m}$ along with associated piping and valves for proper control on filtration rate.The pump of $0.5 \mathrm{HP}$ was used to facilitate back washing.

Because of wall effects, porosity $(\varepsilon)$ is dependent on not only the ratio of particle diameter (d) to container dimension (D), but also the ratio of particle diameter to medium depth of the medium $(\mathrm{H})$. The effective sand particle diameter and filter column dimension were 0.85 and $150 \mathrm{~mm}$, respectively (i.e., d:D, 1:176), and depth of sand medium was $750 \mathrm{~mm}$ (i.e., d:H, 1:882) [14]. At these ratios the porosity for both loose and dense packing is almost the same as the original porosity [15]. Thus, wall and thickness effects did not significantly affect porosity in the filtration studies. This was helpful in maintaining expected porosity. These parameters were helpful in modeling the realistic conditions.

The pilot model was installed at Ichalkaranji water treatment plant, where the clarified water was used for the performance evaluation of alum aided modified filter media. As the raw water used by most of the plants in India is river water and contains humic substances which are responsible for reduction in particle capture by porous medium filter, same water was used for the performance evaluation. The filters were challenged by the water having turbidity in the range of 9 to $12 \mathrm{NTU}$. The $\mathrm{pH}$ of water was in between 7.2 and 7.4 while the temperature of water was around $20^{\circ} \mathrm{C}$.

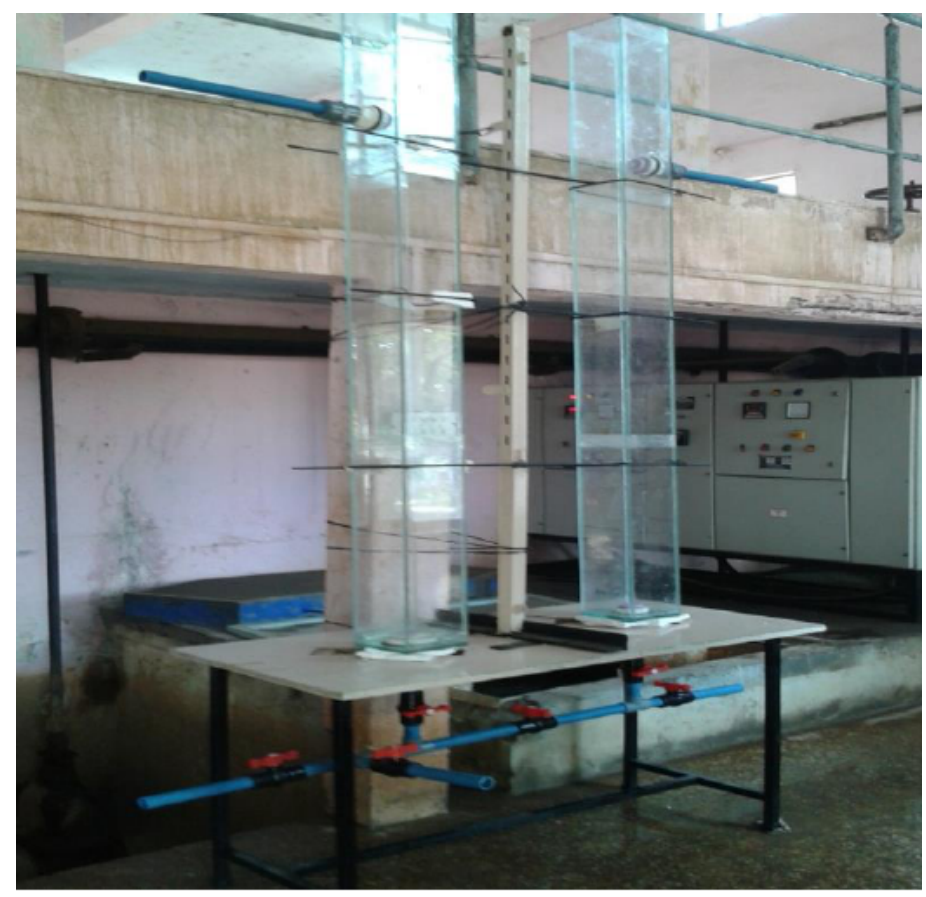

Figure 2 Installed pilot plant at Ichalkaranji W.T.P

The alum $\left[\mathrm{Al}_{2}\left(\mathrm{SO}_{4}\right)_{3} .18 \mathrm{H}_{2} \mathrm{O}\right]$ was chosen to modify a sand-filter medium before challenging the filter. The resulting modification of the filter could include coating the sand surface with precipitated aluminum hydroxides in the pore space of the filter medium. 
The point of zero charge (PZC) of aluminum hydroxide is 9.6 [13]. Thus, at neutral $\mathrm{pH}$, the modified sand media is expected to be positively charged and have an enhanced ability to capture negative colloidal particles. Head loss was also monitored during pretreatment and during the challenge to the filter.

In the initial phase of the research various dosages of alum as 40.76, 20.38, 3.4, 0.85 and 0.68 moles per $\mathrm{m}^{2}$ of filter area, were tried to assess the effect of such aid on conventional filter media and to tentatively determine the better performing dose out of various dosages tried. The same dose was used with changed configuration of sand media having coefficient of uniformity as 1.2 and effective size was $0.85 \mathrm{~mm}$.

The alum dose was given in the form of concentrated alum solution of $2.5 \%$ strength. The dose was given immediate after the backwashing. The dose was applied from top surface of the filter and allowed to percolate by resting the filter for few minutes.

- The turbidity of filter inlet as well as outlet was measured initially at an interval of $1 \mathrm{~min}$. unless the acceptable water quality was produced and afterwards every $15 \mathrm{~min}$. The calibrated nephelometer was used to measure the turbidity. Formazine solution of 40 NTU and distilled water were used for calibration. The instrument was calibrated before every filter run during the study.

- The comparison between the conventional filter and modified filter with alum aid was made on the basis of turbidity of filtrate produced, ripening period, length of filter run and backwashing requirements. The particle count was assumed to be varying as per the turbidity. IS 10500-2012 (revised edition) was used for acceptance criterion of turbidity.[16]

\section{RESULTS AND DISCUSSIONS}

Following are the observations recorded while pilot plant study. Three trials per dose were taken to confirm the behavior and deviation if any. No such deviation was observed. The prominent observations are mentioned below. The results are divided in to two parts. The first part describes the results observed in case of different dosages used with conventional configuration of media for different dosages tried while second part of result describe the results observed with modified configuration of the media and better performing dose observed in initial part. Authors are not claiming that the dose of filter aid tried is the optimum dose.

\subsection{Part 1: Results}

Table 1 Different alum doses tried during the study were as follows.

\begin{tabular}{|c|c|c|}
\hline Sr. No. & $\begin{array}{c}\text { Rate of alum addition per } \mathbf{~ m}^{\mathbf{2}} \text { of area of } \\
\text { filter }\end{array}$ & $\begin{array}{c}\text { Moles of alum addition per } \mathbf{~ m}^{\mathbf{2}} \text { of area } \\
\text { of filter }\end{array}$ \\
\hline 01. & $26.67 \mathrm{~kg}$ & $40.76^{*}$ \\
\hline 02. & $13.33 \mathrm{~kg}$ & $20.38^{*}$ \\
\hline 03. & $2.22 \mathrm{~kg}$ & 3.4 \\
\hline 04. & $0.55 \mathrm{~kg}$ & 0.85 \\
\hline 05. & $0.44 \mathrm{~kg}$ & 0.68 \\
\hline
\end{tabular}

* After first two dosages, it was observed that these dosages were very high and large part of the applied dose is actually getting wasted in the form of initial leaching from the filter media. So the dosages were considerably reduced for next trials. Dosages numerically may look strange as the dose is applied to pilot scale of $0.15 \mathrm{~m} \mathrm{X} 0.15 \mathrm{~m}$ and rounded to the values after converting it as a dose applied per $\mathrm{m}^{2}$ of filter area. 


\subsubsection{Residual turbidity and filter run profiles}

Following graphs represent the residual turbidity and total filter run observed during the experimental study. The residual turbidity of output water was found varying as the turbidity of input water. The performance of alum aided filter column was much more stable as compare to untreated conventional filter column.

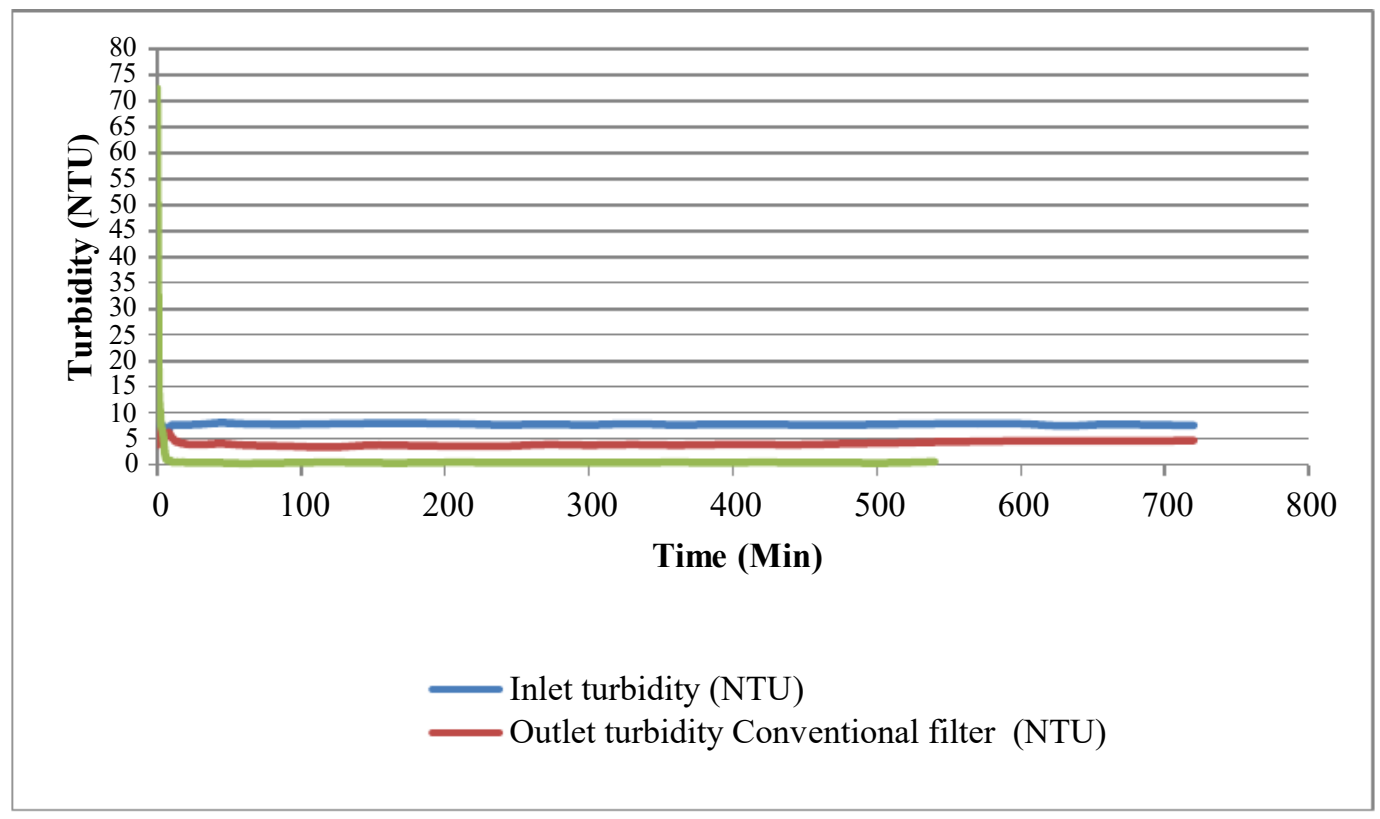

Figure 3 Comparison of 40.76 moles $/ \mathrm{m}^{2}$ alum dose aided RSF and conventional RSF

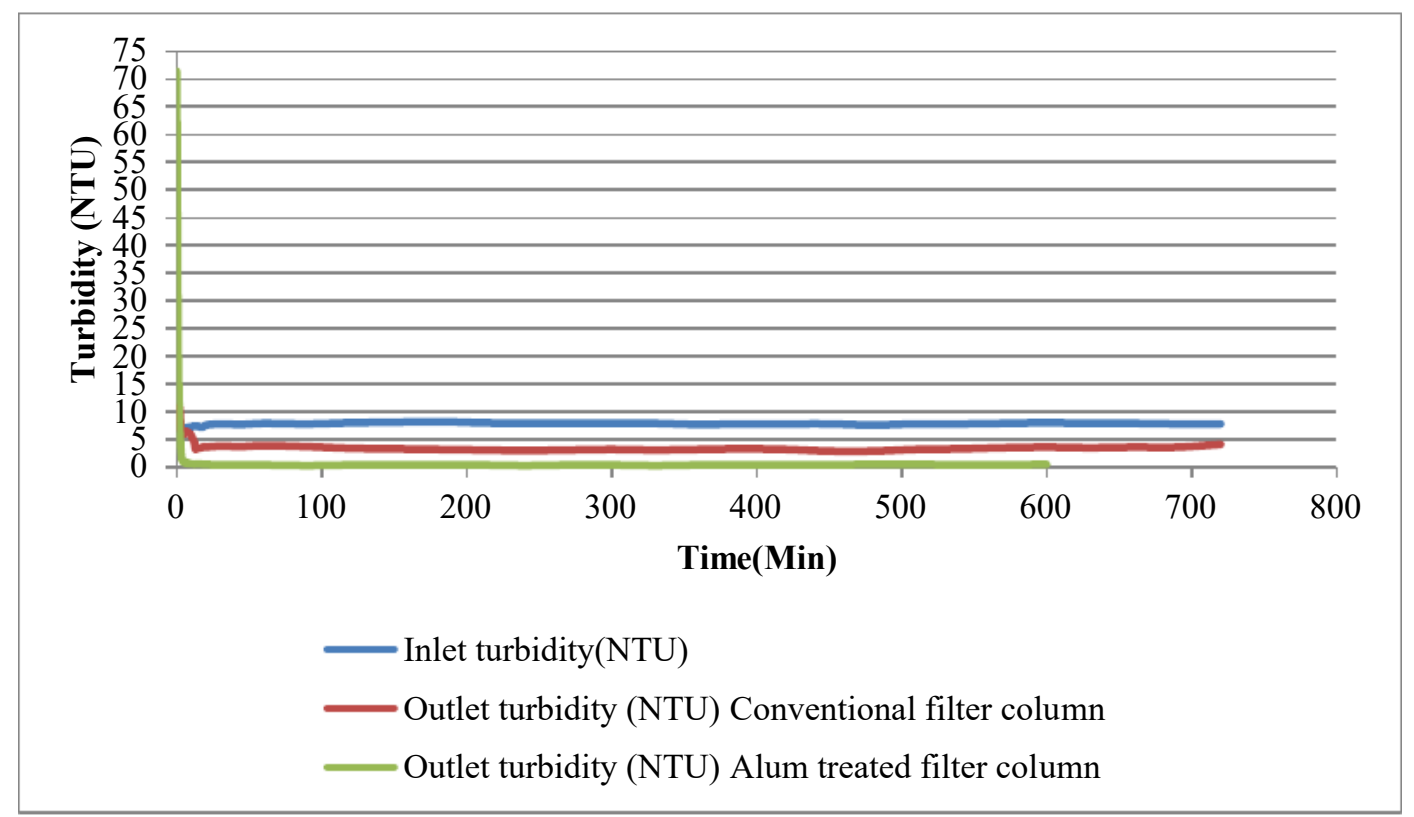

Figure 4 Comparison of 20.38 mole/m²alum dose aided RSF and conventional RSF 
Manoj H Mota, Dr. P S Patil, Dr. V D Salkar

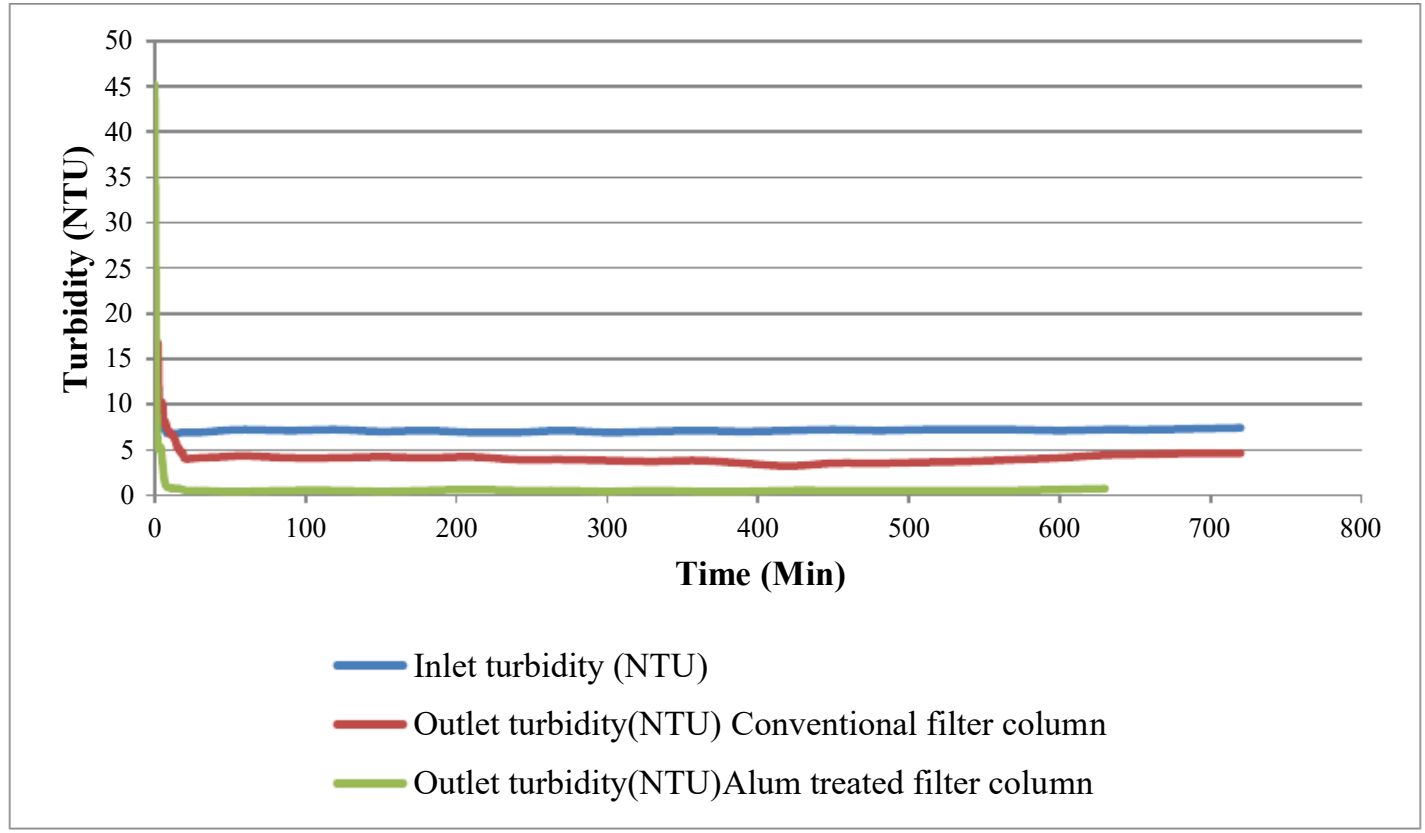

Figure 5 Comparison of $3.4 \mathrm{moles} / \mathrm{m}^{2}$ alum dose aided RSF and conventional RSF

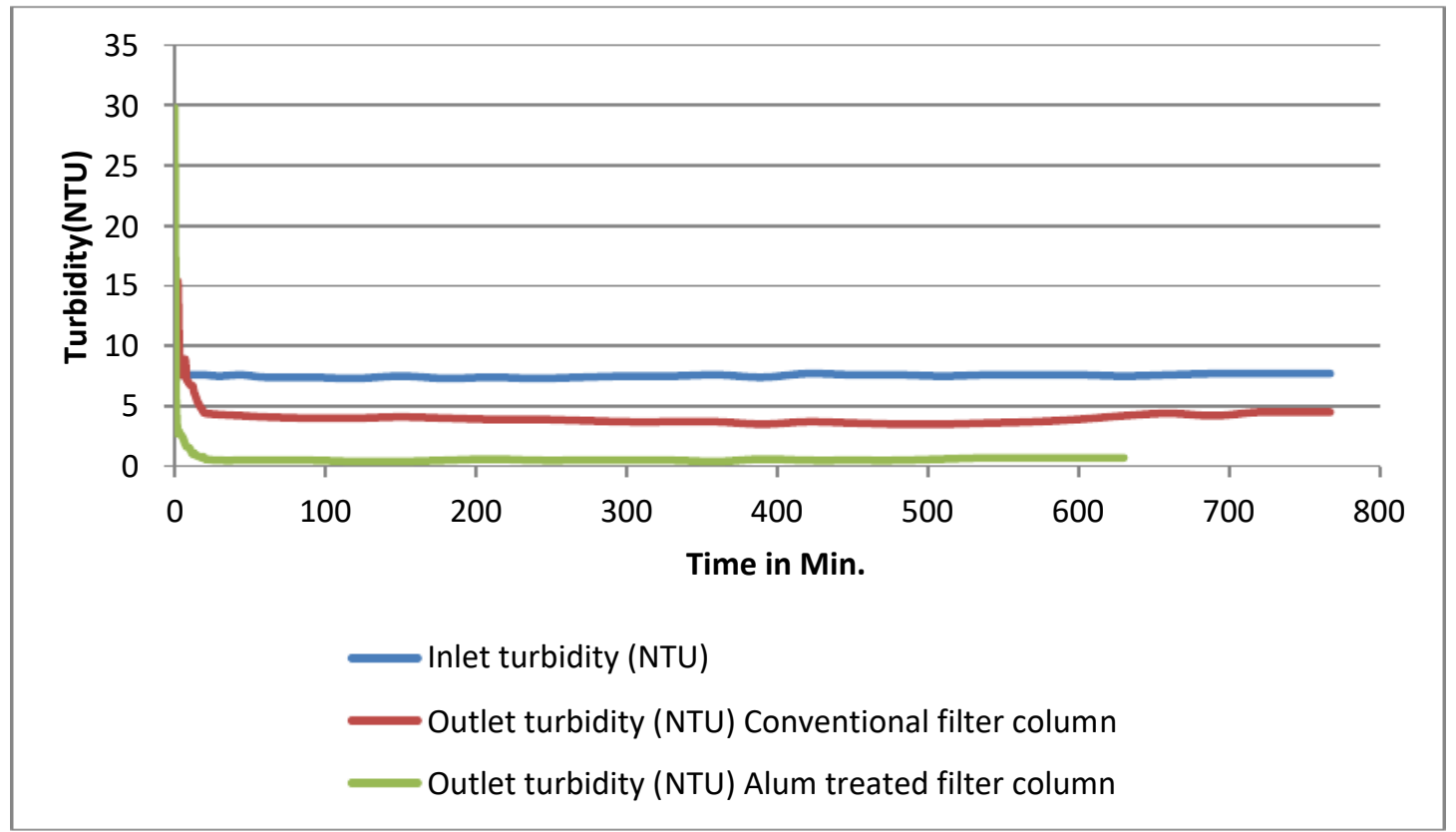

Figure 6 Comparison of $0.85 \mathrm{~mole} / \mathrm{m}^{2}$ alum dose aided RSF and conventional RSF 


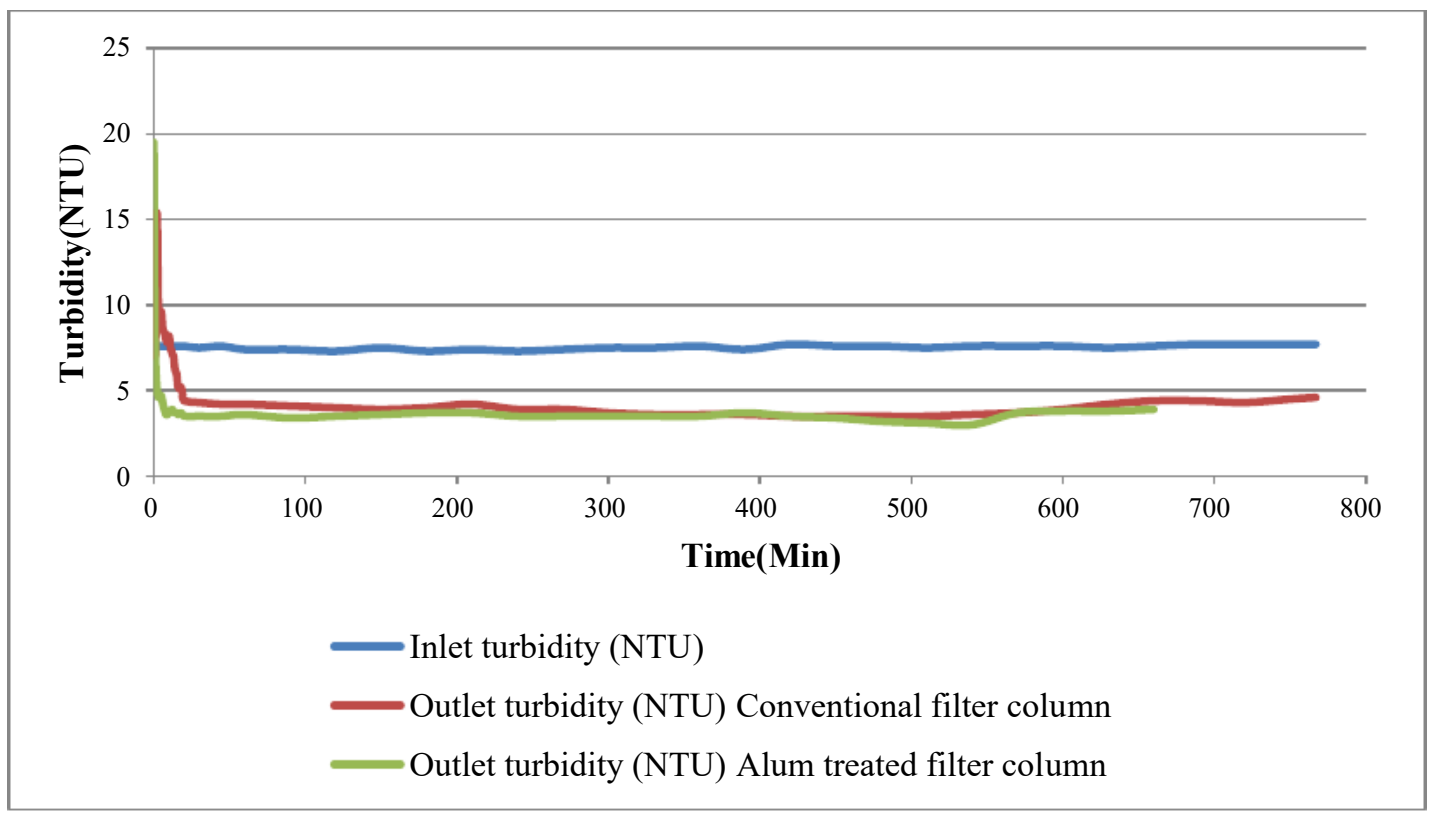

Figure 7 Comparison of $0.68 \mathrm{~mole} / \mathrm{m}$ alum dose aided RSF and conventional RSF

The initial turbidity spike was observed in all dosages tried, due to the leaching of alum solution with filtrate and was not because of the excessive escape of common turbidity causing particles. The same also last for very short period. As the dosage is reduced the turbidity spike observed also was reduced in duration and magnitude. This may result in high aluminum concentration in water filtered in very initial stage in filtration, but it will be taken care itself by getting diluted as filter cycle progresses. It was also observed that the alum aided filter run was ended because of excessive head loss and reduced flow rate, which was expected because of high turbidity removal and clogging of voids by the removal of turbidity causing particles. This demonstrates that the particles removed were strongly held in media body and capable to withstand shear force caused due to flowing water. This phenomenon of clogging can be beneficial for the filter as it will reduce the entry of undesirable matter in to filtrate produced. The ripening period of RSF was also reduced by great extent. As dose increased the extent of filter run was decreased. But the quality of filtered water was remained almost same in terms of overall residual turbidity. Considering all parameters, the alum dose of $0.555 \mathrm{~kg} / \mathrm{m}^{2}$ i.e. 0.85 moles $/ \mathrm{m}^{2}$ was adjudged as better performing dose among the various dosages tried.

From the experimental analysis it was quite clear that the alum aided filtration proved to be very effective method to improve the performance of conventional rapid sand filters in terms of turbidity removal. The overall quality of water produced was far superior as compare to conventional filter, which could result in reduction in the requirement of disinfectant as well and in turn the undesirable DBPs [17]. The major limitations observed were the reduction of filter run as well as low rate of filtration along with high backwash requirement.

The second part of the research was devoted to working out possible solution on limitations observed in first part. The low rate of filtration as well as reduced filter run was addressed by increasing the effective size of filter media to $0.85 \mathrm{~mm}$ and decreasing the coefficient to 1.2 . The alum dose tried was $0.85 \mathrm{moles} / \mathrm{m}^{2}$. Once again the authors are making it clear that the dose tried may not be optimum under the modified conditions of media. 
Table 2 Summary of the results obtained is as follows:

\begin{tabular}{|c|c|c|c|c|c|c|c|c|c|c|c|}
\hline \multirow[t]{2}{*}{$\begin{array}{l}\text { Sr. } \\
\text { No. }\end{array}$} & \multirow{2}{*}{$\begin{array}{c}\text { Alum Dose } \\
\text { Moles per } \\
\text { m }^{2}\end{array}$} & \multicolumn{3}{|c|}{ Filter run (min) } & \multicolumn{3}{|c|}{ Ripening period (min) } & \multicolumn{2}{|c|}{$\begin{array}{c}\text { Average residual } \\
\text { turbidity (NTU) }\end{array}$} & \multicolumn{2}{|c|}{$\begin{array}{l}\text { Backwashing water } \\
\text { required (lit) }\end{array}$} \\
\hline & & 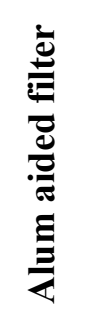 & 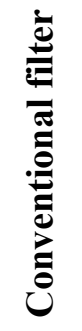 & 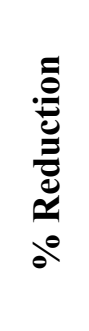 & 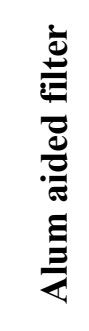 & 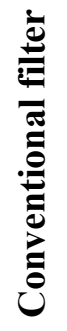 & 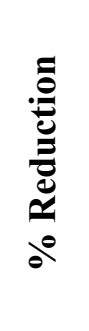 & 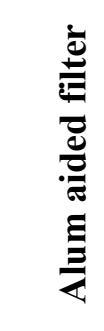 & 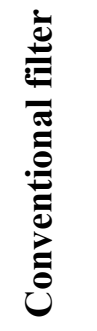 & 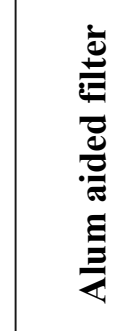 & 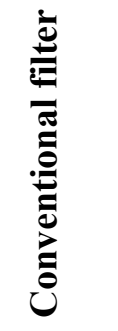 \\
\hline 01 & 40.76 & 540 & 745 & 27.5 & 5 & 12 & 58.3 & 4.5 & 0.5 & 530 & 340 \\
\hline 02 & 20.38 & 600 & 750 & 20.0 & 3 & 11 & 72.7 & 3.4 & 0.4 & 480 & 355 \\
\hline 03 & 3.4 & 630 & 790 & 20.2 & 5 & 17 & 70.6 & 3.5 & 0.5 & 455 & 360 \\
\hline 04 & 0.85 & 630 & 767 & 17.8 & 2 & 17 & 88.2 & 3.6 & 0.5 & 435 & 350 \\
\hline 05 & 0.68 & 660 & 777 & 15.1 & 3 & 18 & 83.3 & 3.9 & 3.5 & 370 & 360 \\
\hline
\end{tabular}

\subsection{Mathematical modeling of the concept}

Fig. 8, 9 and 10 represents the mathematical modeling of the application of alum as filter dose for conventional filter media. 'Microsoft excel' is used to derive these models using the observations recorded during this research.

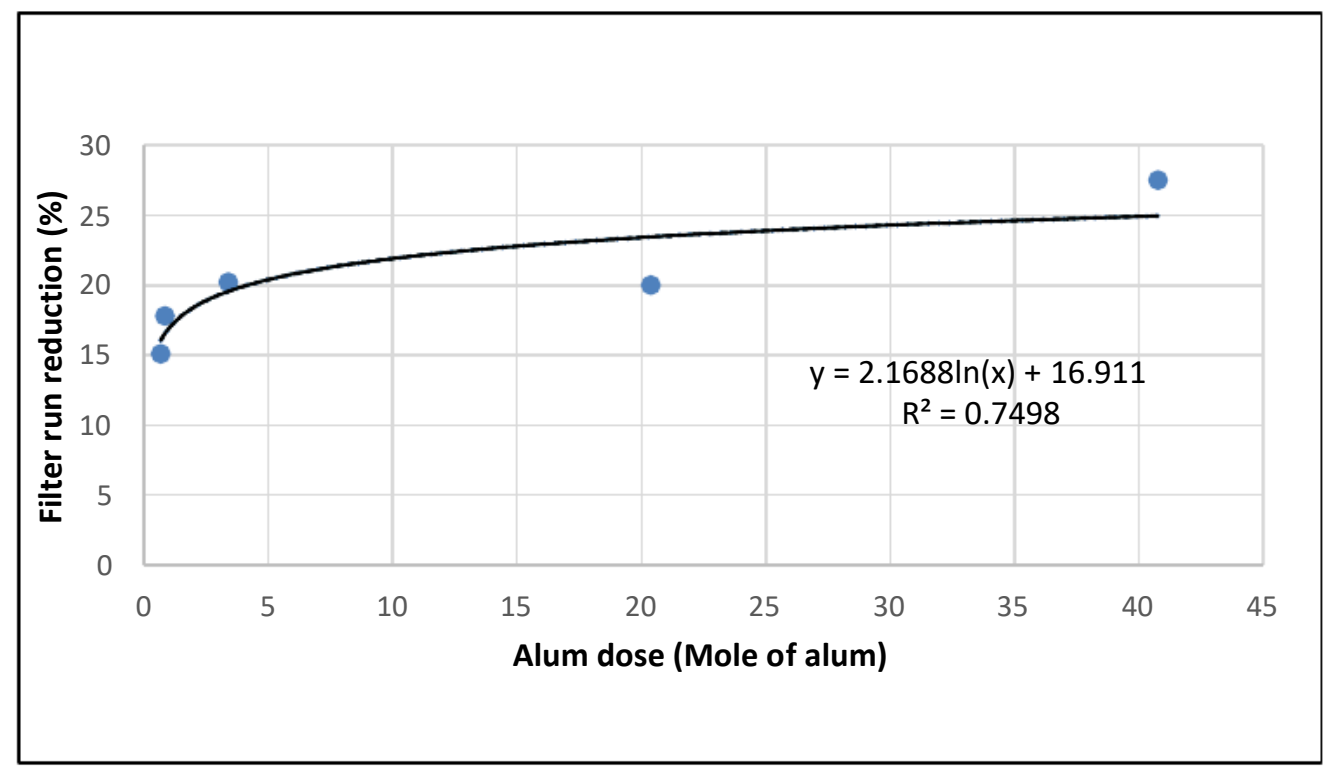

Figure 8 Relation between reduction in filter run and alum dose 
Enhancement of Performance of Filter Using Deep Bed Mono Media with Alum as Filer Aid

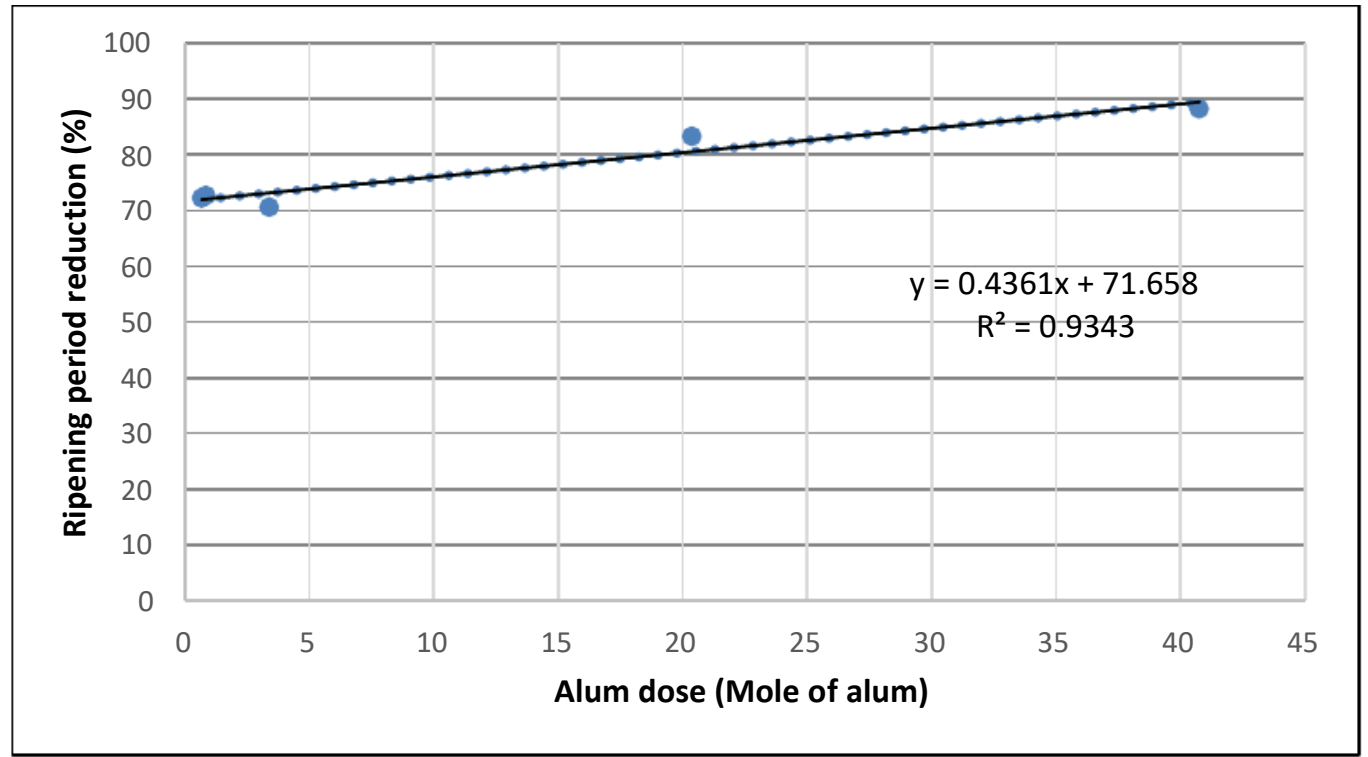

Figure 9 Relation between reduction in ripening period and alum dose

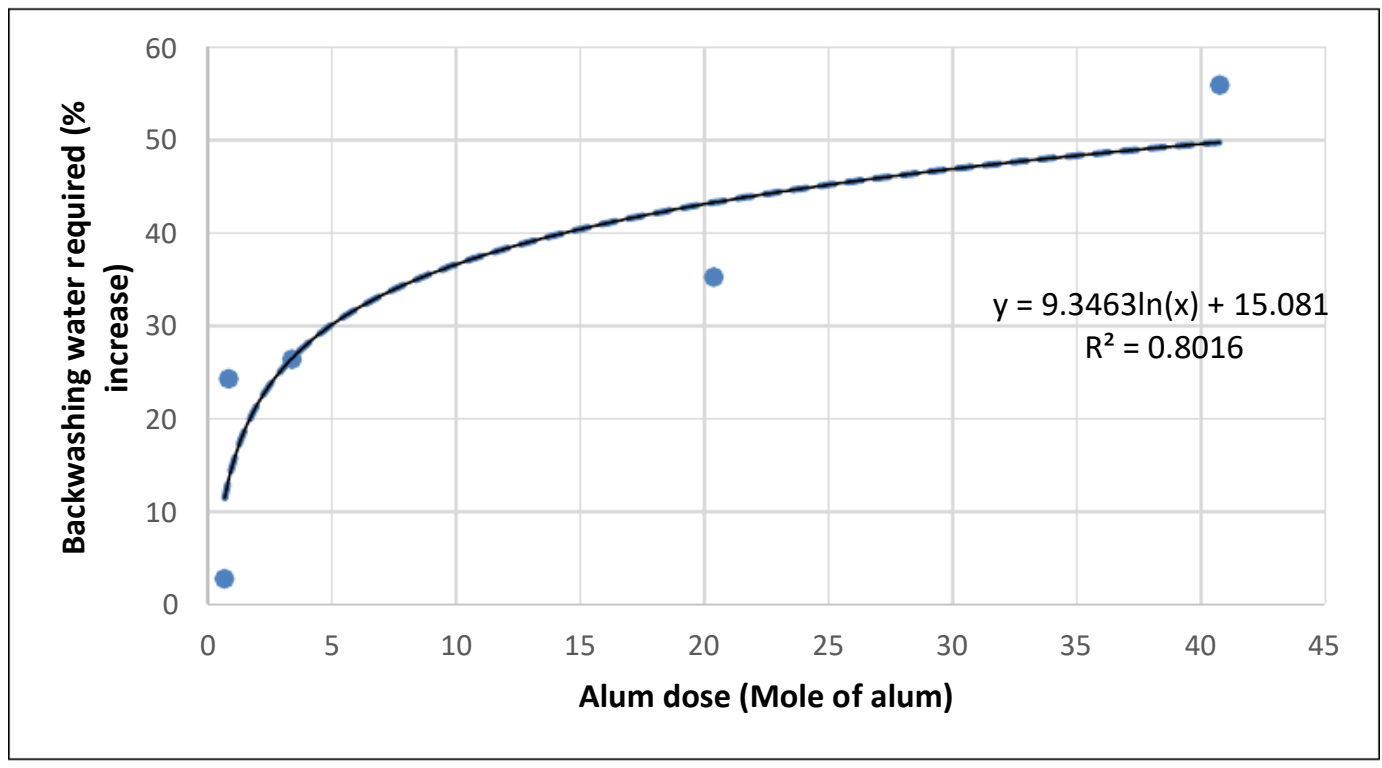

Figure 10 Relation between increase in backwashing water requirement and alum dose

\subsection{Part 2: Results}

The results obtained in second part of the research show that turbidity removal was significantly improved in the pretreated filter with modified sand media configuration as compared with the untreated conventional filter and that the agreement of filter performance in replicate experiments was excellent. Along with this the rate of filtration as well as length of filtration cycle also was increased. The fig. 11 shows the observation regarding the turbidity removal as well as length of filter run recorded under the modified condition and its comparison with conventional filter. Fig. 12 indicates the flow rate observed during the research.

\subsubsection{Residual turbidity, filter run and flow rate/ filtration rate profiles:}

The figure 11 shows the inlet turbidity and residual turbidity along with total filter run observed during the experimental run conducted with modified media configuration and its comparison with conventional filter while figure 12 shows the flow rate profile observed. 


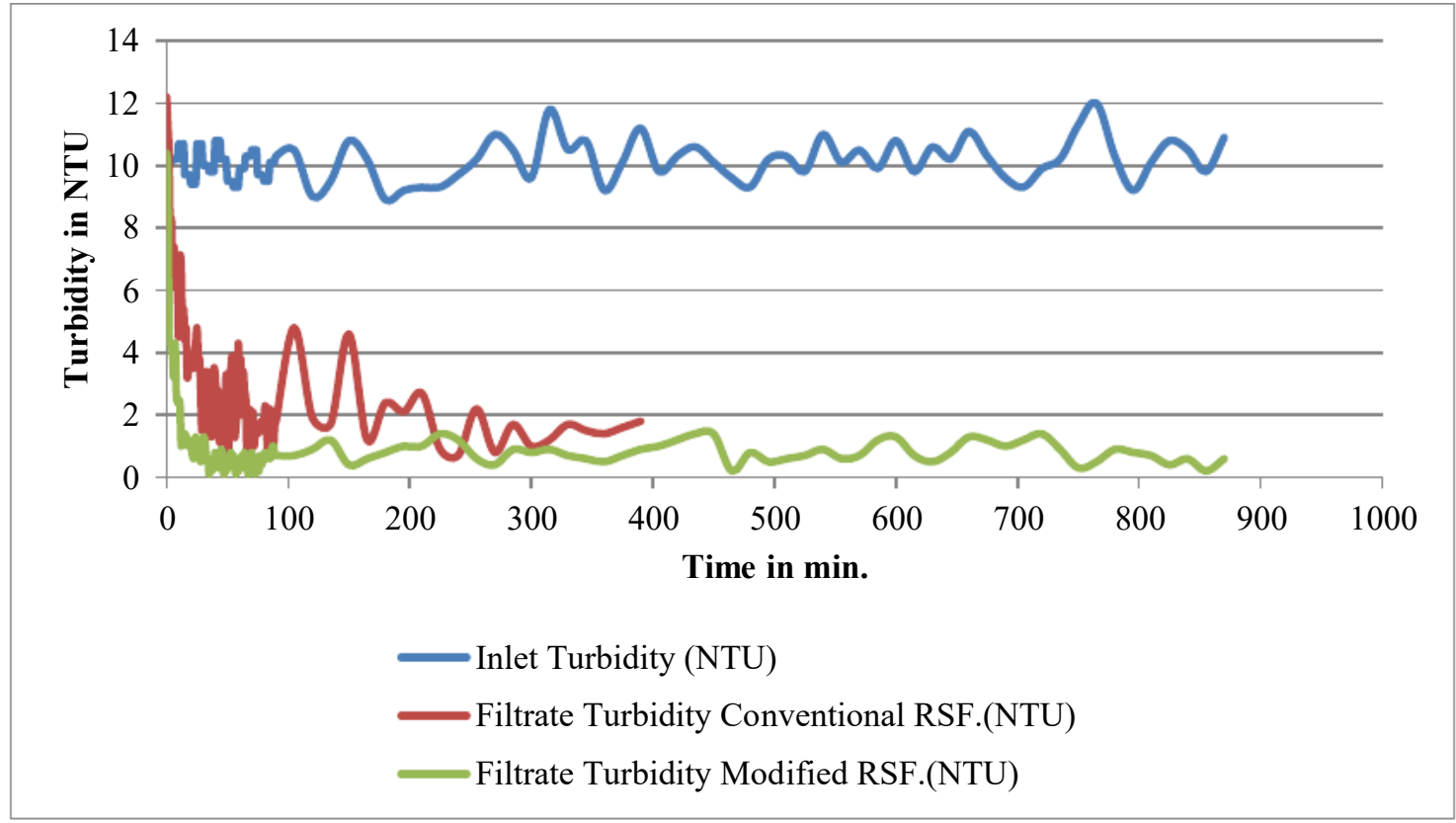

Figure 11 Graph showing the residual turbidity for complete filter run.

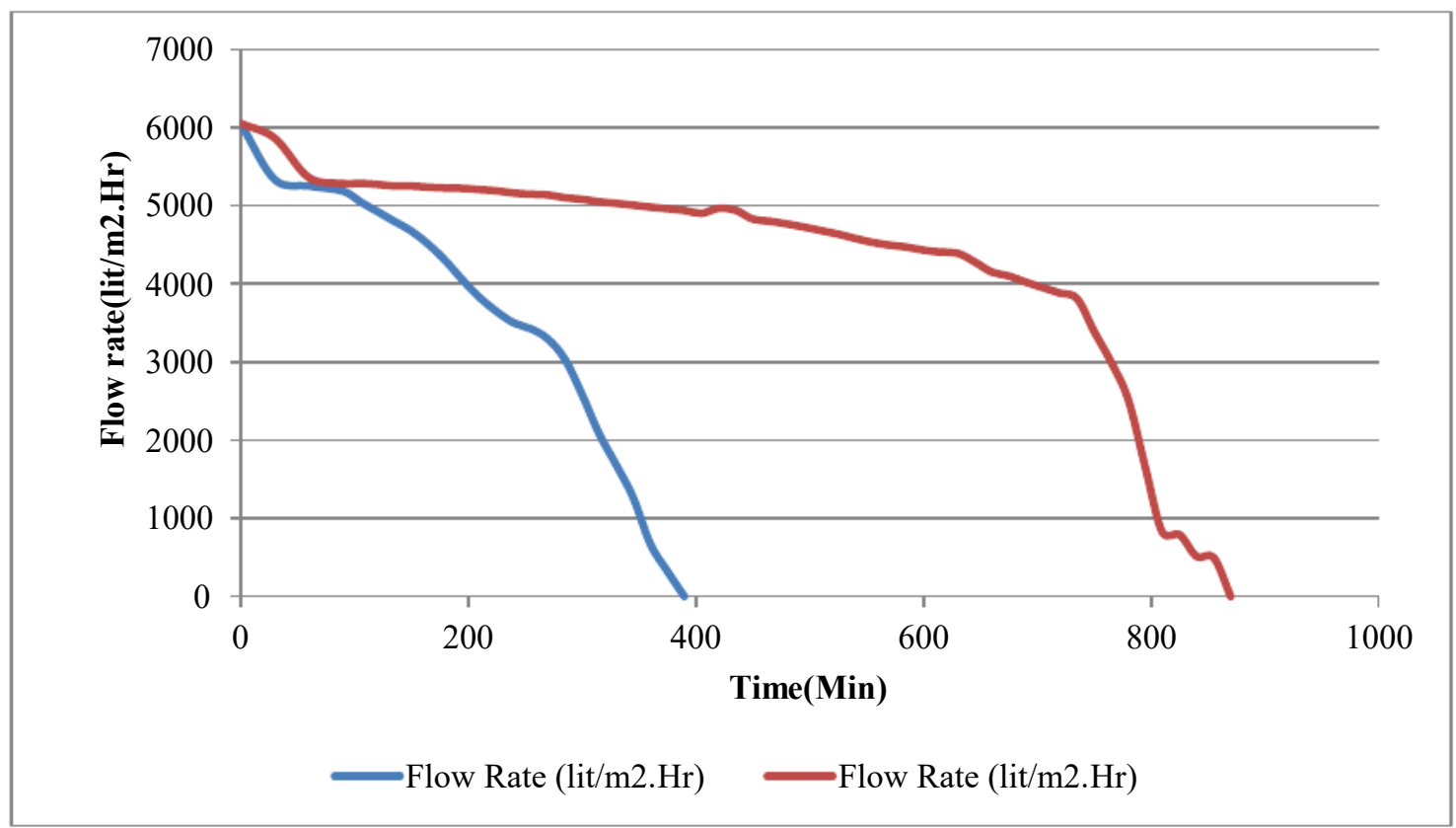

Figure 12 Graph showing the variation in flow rate for complete filter run.

The amount of backwash water consumed by conventional as well as modified RSF, following conventional method of backwashing was as follows.

Table 3 Observations recorded during backwashing for pilot scale model.

\begin{tabular}{|l|c|c|c|}
\hline & Time (MIN) & $\begin{array}{c}\text { Total Water Consumed in } \\
\text { backwashing }\end{array}$ & Back wash rate \\
\hline Conventional RSF. & 20 & $336.15 \mathrm{lit}$ & $0.747 \mathrm{~m} / \mathrm{min}$ \\
\hline Modified RSF. & 25 & $420.19 \mathrm{lit}$ & $0.747 \mathrm{~m} / \mathrm{min}$ \\
\hline
\end{tabular}

Total water filtered in one filter cycle in case of pre-treated filter with more uniform and coarser media was found to be $150 \%$ more along with total filter run extended by $100 \%$. The increase in average filtration rate was observed to be $100 \%$. So even though the backwashing 
requirement was higher (around 25\%) the net water required for the backwashing was saved by $50 \%$.

From the study made to evaluate the performance of the innovative media of higher effective size and lower coefficient of uniformity along with the alum as filter aid was able to produce the filtrate with much better quality as compare to conventional filer used particularly in developing countries like India where still use of dual media or multi-media filters is distance from reality because of unavailability of anthracite coal media and the filter to waste kind of techniques are also not feasible luxury the plants can afford.

The performance was found to be more stable with high rate of filtration. The results indicated that the combination of course and more uniform media with alum dose can perform exceptionally well as compare to conventional rapid sand filters. The modified surface properties (as a result of media pre-treatment) may result in better particle removal from the very initial phase of the filter run. The attached particle may the act as collection sites for extended part of filter cycle. Using alum dose as filter aid, results in increased particulate removal. The media of higher effective size and low coefficient of uniformity also permits better utilization of the entire depth of the filter bed.The observations also demonstrated the reduced chances of break-through. The extended run and high rate of filtration was also adding the huge advantage in current scenario where the need of physical modification in case of capacity augmentation can be eliminated as far as filtration is concerned.

The allied benefits may include the lower disinfectant need and lower chances of the ill effects of DBPs, which are relatively common in case of raw water containing organic matter having a river as a source where large number of agriculture is practiced on the banks. Detailed discussion on these benefits is beyond the scope of this paper.

\section{CONCLUSION}

From the study made to evaluate the effect of Alum aided RSF, following conclusions were made

The use of alum solution as filter aid is improving the filtrate quality substantially. The residual turbidity in case of pre-treated conventional filtration was found in the range of $0.5 \mathrm{NTU}$ which was really appreciable as compare to unaided filtration. The ripening period was also suppressed substantially. Higher dose of alum is resulting in better turbidity removal but lower filter run and higher head loss as well as higher backwash requirement.

In case of filter media of higher effective size and lower coefficient of uniformity along with alum as filter aid can be boon to overall performance of water treatment plants in developing countries. It has a potential to remove the high turbidity along with extended filter run and net reduced backwashing requirement. Because of high turbidity removal the dose of disinfectant i.e. chlorine can be reduced which will reduce the possible formation of DBPs and its ill effects on the health of consumers.

\section{ACKNOWLEDGMENT}

The author wants to acknowledge the support provided by the Hydraulic engineer, Ichalkaranji Municipal Corporation for permitting the study to carry out in their premise of water treatment plant.

\section{REFERENCES}

[1] Amburgey, J. E., and Amirtharajah, A. (2005). "Strategic filter backwashing techniques and resulting particle passage.” Journal of Environmental Engineering, 131(4), 535-547. 
[2] Denver.O'Leary, K. C., Eisnor, J. D., and Gagnon, G. A. (2003). "Examination of plant performance and filter ripening with particle counters at full-scale water treatment plants." Environmental Technology, 24(1), 1-9.

[3] Gitis, V., Adin, A., Nasser, A., Gun, J., and Lev, O. (2002). "Fluorescent dye labeled bacteriophages-A new tracer for the investigation of viral transport in porous media: 2 . Studies of deep-bed filtration." Water Research,36(17), 4235-4242.

[4] Letterman, D. R. (1999). Water quality and treatment, 5th Ed., American Water Works Association,

[5] Franchi, A., and O'Melia, C. R. (2003). "Effects of natural organic matter and solution chemistry on the deposition and reentrainment of colloids in porous media." Environmental Science Technology, 37(6), 1122-1129.

[6] Gjessing, E. T. (1976). 'Physical and chemical characteristics of aquatic humus, Ann Arbor, MI.

[7] Pernitsky, D. J., and Edzwald, J. K. (2006). "Selection of alum and polyaluminum coagulants: Principles and applications.” J. Water Supply: Res. Technol.-AQUA, 55(2), 121-141.

[8] V.D. Salkar, A.R. Tembhurkar, (2019), 'Effect of $\zeta$-potential of influent particles on initial filter coefficient for rapid sand filter', Journal of Water Chemistry and Technology ISSN 0204-3556. $41,1-15$

[9] Gary S. L., Alan F. H., Michael J. C., John G., Jack L., Claudia H., \& John Wi (2005), 'Controlling Turbidity Spike with Alum, Iron' .American Water Works Association, Opflow.

[10] Pizzi Nick,( 2000) 'Optimizing Your Plant's Filter Performance' (2000) Journal of American Water Works Association, Op-flow, 26(6), 37-38.

[11] Po-Hsun Lin, Leonard W., \& Monroe L, (2011) 'Comparison of the Ability of Three Coagulants to Enhance Filter Performance,' Journal of Environment Engineering, vol 137, 371-376.

[12] Po-Hsun Lin, Leonard W., \& Monroe L, (2012) 'Enhanced Particle Capture through Aluminum Hydroxide Addition to Pores in Sand Media,' Journal of Environment Engineering, vol 138, 816.

[13] Scholtz, E. C., Feldkamp, J. R., White, J. L., and Hem, S. L. (1985). "Point of zero charge of amorphous aluminum hydroxide as a function of adsorbed carbonate." J. Pharm. Sci., 74(4), $478-481$.

[14] Lang J S, giron J J, Hansen A T, Trussell RR, Hodges W E,(1993)' Investigating Filter Performance as a Function of Filter Size to Media Size', Journal Of Water Resources Association 85(10), 122-130.

[15] Zou R.P and Yu A. B, (1995) 'The packing of sphere in a cylindrical container, the thickness effect', Chemical Engineering Science, vol. 50(9), 1504-1507.

[16] 'IS 10500:2012, (2015) Indian standard Drinking water-Specification - second revision, Bureau of Indian standards, New Delhi,1.

[17] Hua, G., and Reckhow, D. A. (2007). "Characterization of disinfection byproduct precursors based on hydrophobicity and molecular size." Environmental Science Technology, 41(9), 3309_ 3315 .

[18] T. Balamurali and B. Preetha, (2014), The Separation of Copper, Nickel and Chromium Metal Ions Using with Ultrafiltration Membrane: Effect of Polymer Membrane Compositions, International Journal of Advanced Research in Engineering and Technology (IJARET), Volume 5, Issue 6, pp. 144-162

[19] Pakanati Chandra Sekhar Reddy, K.C. Vinuprakash and Sija Arun, (2018), Treatment of Domestic Wastewater Using Vermi-Biofiltration System with and Without Wetland Plants, International Journal of Civil Engineering and Technology, 9(4), pp. 412-423

[20] SukmasariAntaria, Fenti Daud and Nenny, (2018), Utilization of Natural Zeolite South Sulawesi as Filtration Materialfor Reducing Heavy Metal Nickel (Ni), International Journal of Civil Engineering and Technology, 9(9), pp. 1876- 1885.

[21] Abd. Rakhin and Nurnawaty, (2017), Vegetated Pond Models to Improve Infiltration Rate with Rainfall Intensity Variations. International Journal of Civil Engineering and Technology, 8(10), pp. 667-676.

[22] Dr. Al-Tufaily, M. A. M. and Zwayen, D. M. A. -M. (2015), Water Filtration by using of Glass, Plastic and Aluminum Filings as a Filter Media. International Journal of Advanced Research in Engineering and Technology, 6(1), pp. 84-104. 